\title{
The relationship between the biotype of Klebsiella species and their pathogenicity
}

\author{
R. J. FALLON \\ From the Department of Laboratory Medicine, Ruchill Hospital, Glasgow
}

SYNOPSIS Using the biochemical scheme of Cowan, Steel, Shaw, and Duguid (1960) 209 strains of the genus Klebsiella isolated from sputum were classified and their relationship to disease in the patients from whom they were isolated was examined. $K$. aerogenes predominated and was seldom of proven pathogenicity. $K$. ozaenae was the next most common species isolated and was of pathological significance in $38 \%$ of cases. $K$. edwardsii var edwardsii, $K$. edwardsii var atlantae, and $K$. pneumoniae were less commonly isolated but were more frequently associated with severe disease than $K$. aerogenes and $K$. ozaenae.

Foster and Bragg (1962) observed that certain of the biochemical types of Klebsiella as classified by Cowan et al (1960) appeared to be associated with severe chest disease more frequently than others. Their observations were extended by Darrell and Hurdle (1964) in their study of Klebsiella in chest infections but neither series contained many organisms classified as Klebsiella ozaenae. This organism has been isolated from many sputa submitted to this laboratory for examination and in view of this finding it was thought to be of interest to extend the observations of these workers. A preliminary study was reported briefly in 1968 (Fallon, 1968). Further points of interest were to see how the biochemical classification correlated with capsular serotype and also whether any significant biochemical variations occurred in strains isolated from the same patient over a period of two or more years.

\section{Materials and Methods}

CASES

The records of cases seen at Ruchill Hospital from 1962 to 1967 either as inpatients or outpatients, from whose sputum Klebsiella sp were isolated, were reviewed in order to define what relationship the organism bore to the patient's clinical condition. Nearly all patients had either suspected or established respiratory infection so that, except in a very few cases, it was impossible to state that the organism

Received for publication 18 May 1973. isolated from their sputum bore no relationship to their condition, ie, the Klebsiella may have been secondary invaders even although they were not the primary bacterial pathogens. It was possible, however, to try and assess, by the persistence of an organism or its disappearance from the sputum, what relationship it bore to an acute infection where one occurred. The criteria on which the significance of the organisms isolated from sputum was assessed are set out in table I.

\section{EXAMINATION OF SPUTUM}

Sputum was treated with buffered pancreatin (Oxoid) by the method of Rawlins (1953) and the centrifuged deposit from the resulting homogenized specimen was cultured on $5 \%$ horse blood agar and MacConkey agar. In addition a blood agar plate was inoculated for direct antibiotic sensitivity tests and a Gram film was made. Klebsiella sp were initially recognized as non-motile, Gram-negative rods growing as moist and often mucoid non-pigmented colonies. They were catalase positive, oxidase negative and fermented glucose in the medium of Hugh and Leifson (Cowan and Steel, 1965). Organisms fulfilling these criteria were then examined using the tests shown in table II with the exception of examination for the presence of fimbriae.

In addition, strains examined for capsular serotype (vide infra) were examined for the production of acid from salicin, xylose, adonitol, cellobiose, and inositol. They were also examined for deamination of phenylalanine and reduction of nitrate.

Strains were classified biochemically as described 
Associated with Disease

Isolated from lung at necropsy

Present in acute but not convalescent specimen

Present in acute specimen. Patient recovered after appropriate antibiotic
Not Primarily Responsible for Disease

Persistently present despite recovery of patient (especially if other pathogens disappeared coincident with recovery)

Appeared transiently during illness without clinical deterioration.

Only one sputum specimen obtained but patient recovered on penicillin therapy.

Not isolated at necropsy but other pathogens present

No attributable illness

Table I Assessment of significance of isolation of Klebsiella from sputum

\begin{tabular}{|c|c|c|c|c|c|c|}
\hline & $K$. aerogenes & $K$. pneumoniae & $\begin{array}{l}\text { K. edwardsii- } \\
\text { edwardsii }\end{array}$ & $\begin{array}{l}\text { K. edwardsii- } \\
\text { atlantae }\end{array}$ & $\begin{array}{l}\text { K. rhino } \\
\text { scleromatis }\end{array}$ & K. ozaenae \\
\hline Glucose (gas) & $\cdots$ & - & - & $\cdots$ & - & d \\
\hline Mannitol (acid) & $\cdots$ & $\cdots$ & 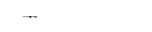 & - & - & $\cdots$ \\
\hline Dulcitol (acid) & d & & - & - & - & - \\
\hline Lactose (acid) & .. & & $(-)$ & $(-)$ & - & $(\cdot)$ \\
\hline Sucrose (acid) & . & .. & - & - & -- & d \\
\hline Indole & - & $\rightarrow$ & - & - & - & - \\
\hline Gelatin liquefaction & - & - & - & - & - & - \\
\hline $\mathrm{H}_{2} \mathrm{~S}$ & - & - & - & - & - & - \\
\hline MR & - & -. & $\mathrm{d}$ & - & - & $\ldots$ \\
\hline VP & $\cdots$ & - & - & d & - & - \\
\hline Urease & & - & + & - & - & d \\
\hline Lysine decarboxylase & $\therefore$ & & - & $\rightarrow$ & - & $d$ \\
\hline Arginine decarboxylase & - & - & - & - & - & - \\
\hline Ornithine decarboxylase & - & - & - & - & - & - \\
\hline $\mathrm{KCN}$ & $\cdots$ & - & $\because$ & - & - & -. \\
\hline Gluconate & $\cdots$ &.. & - & $\mathrm{d}$ & - & - \\
\hline Malonate & $\cdots$ & & d & - & $\cdots$ & - \\
\hline Fimbriae $^{1}$ & + & & - & - & - & - \\
\hline MacConkey (growth) & $\because$ & $\ldots$ & - & - . & 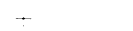 & - \\
\hline Citrate & + & $\therefore$ & d & - & - & $d$ \\
\hline
\end{tabular}

Table II Diagnostic scheme of Cowan and Steel (1961)

${ }^{1}$ Not tested for

by Cowan et al (1960) with the modifications introduced by Cowan and Steel (1961) (table II).

\section{BIOCHEMICAL TESTS}

The methods used were the same as those described by Cowan and Steel (1965) with the following exceptions or where relevant, alternatives. Unless stated cultures were incubated at $37^{\circ} \mathrm{C}$ for 48 hours.

\section{Fermentation of carbohydrates}

Strains examined for capsular serotype or for reproducibility of fermentation pattern (see table IV) were incubated for up to three weeks at $37^{\circ} \mathrm{C}$ before a test was accepted as negative for acid or gas production.

\section{$\mathrm{H}_{2} \mathrm{~S}$ production}

Organisms for this test were grown in peptone water.

\section{Voges-Proskauer reaction}

Barritt's method was used.

\section{Urease production}

Christensen's urea medium was used.

\section{Decarboxylase reactions}

The method of Møller was used. Strains were not examined for fimbriae nor for $\beta$-galactosidase activity.

\section{Serological studies}

The capsular antigens of a proportion of the strains studied were kindly determined by Dr Ida Ørskov of the State Serum Institute, Copenhagen.

\section{Results}

BIOTYPES OF KLEBSIELLA ISOLATED

Two hundred and nine patients were included in this study. The details of the biochemical types of Klebsiella isolated from their sputa are summarized in table III. The majority of strains were classified either as $K$. aerogenes or $K$. ozaenae.

Strains of $K$. ozaenae were of a fairly constant colonial morphology on blood agar forming colourless or slightly creamy, low, convex, mucoid colonies which were quite distinct from the large cream-coloured, high-convex, colonies of $K$. edwardsi 


\begin{tabular}{lccc}
\hline Type of Klebsiella & \multicolumn{2}{c}{ Number of Patients } & Total \\
\cline { 2 - 3 } & $M$. & $F$. & \\
\hline K. aerogenes & 63 & 29 & 92 \\
K. ozaenae & 71 & 15 & 86 \\
K. edwardsii var edwardsii & 13 & 6 & 19 \\
K. edwardsii var atlantae & 6 & 1 & 7 \\
K. pneumoniae & 3 & 2 & 5 \\
& 156 & 53 & 209 \\
\hline
\end{tabular}

Table III Klebsiella sp. examined

and the medium-sized moist, cream-coloured colonies of $K$. aerogenes.

In some patients with purulent chronic bronchitis $K$. ozaenae persisted in the sputum for over three years. This was not seen with other Klebsiella sp. In one patient the colonial morphology of the strain of $K$. ozaenae isolated repeatedly from her sputum was atypical in that this strain consistently produced small mucoid colonies which would often have been missed on inspection of the blood agar plate, on the occasions when they were present in relatively small numbers, had not either the McConkey agar shown a mucoid smear of growth in the well of the plate, or the patient's name been noted and closer re-examination of the plate been carried out.

BIOCHEMICAL STABILITY OF STRAINS OF K. ozaenae.

Biochemical investigation

There was a close correlation between the results obtained by the late K. Patricia Carpenter at the Dysentery Reference Laboratory, Colindale, and this laboratory using the various biochemical tests described by Cowan et al (1960) for the classification of strains of Klebsiella except for the production of gas from glucose. When tested at Colindale five strains produced acid only and 11 acid and gas from glucose compared with 13 strains producing acid only and three acid and gas at Ruchill. It was considered that this difference could have been due to the different makes of peptone used by our laboratories. Evans' peptone was used at Colindale and Oxoid peptone at Ruchill. However, when peptone water sugars from both laboratories were inoculated in parallel with a wide range of stock cultures of Enterobacteriaceae identical results were obtained. Hence variation between the two laboratories may have reflected an intrinsic variability in the reactions of $K$. ozaenae. This possibility was examined further with strains of $K$. ozaenae isolated on more than one occasion from individual patients. It was found that gas production from glucose was variable as occasionally was that from other sugars. It could well be argued that we were examining different strains of $K$. ozaenae from a particular patient, but, as noted above, the atypical colonial appearance was noted in every strain isolated and studied from one of the patients (patient $A$ in table IV).

Table IV shows the variability of biochemical reaction obtained with strains isolated from five patients. (The following were negative and never varied: dulcitol fermentation, indole production, gelatin liquefaction, hydrogen sulphide production

\begin{tabular}{|c|c|c|c|c|c|c|c|c|c|c|c|c|c|c|c|}
\hline & \multicolumn{15}{|c|}{ Patient } \\
\hline & $A$ & & & $B$ & & & $C$ & & & $D$ & & & $E$ & & \\
\hline No. of strains & 14 & & & 14 & & & 4 & & & 10 & & & 7 & & \\
\hline Test result & + & & - & - & & - & + & & - & + & & - & + & & - \\
\hline $\begin{array}{l}\text { Test } \\
\text { MR } \\
\text { VP } \\
\text { Urease } \\
\text { Lysine } \\
\text { KCN }{ }^{1} \\
\text { Citrate }\end{array}$ & $\begin{array}{r}11 \\
1 \\
4 \\
0 \\
8 \\
2\end{array}$ & & $\begin{array}{r}3 \\
13 \\
10 \\
14 \\
3 \\
12\end{array}$ & $\begin{array}{r}14 \\
0 \\
1 \\
0 \\
7 \\
0\end{array}$ & & $\begin{array}{r}0 \\
14 \\
13 \\
14 \\
2 \\
14\end{array}$ & $\begin{array}{l}4 \\
0 \\
0 \\
2 \\
2 \\
0\end{array}$ & & $\begin{array}{l}0 \\
4 \\
4 \\
2 \\
2 \\
4\end{array}$ & $\begin{array}{r}10 \\
0 \\
0 \\
0 \\
5 \\
1\end{array}$ & & $\begin{array}{r}0 \\
10 \\
10 \\
10 \\
1 \\
9\end{array}$ & $\begin{array}{l}7 \\
0 \\
0 \\
0 \\
3 \\
0\end{array}$ & & $\begin{array}{l}0 \\
7 \\
7 \\
7 \\
3 \\
7\end{array}$ \\
\hline $\begin{array}{l}\text { Glucose } \\
\text { Mannitol } \\
\text { Lactose } \\
\text { Sucrose }\end{array}$ & $\begin{array}{c}A \& G \\
8 \\
10 \\
9 \\
5\end{array}$ & $\begin{array}{l}A \\
6 \\
4 \\
5 \\
4\end{array}$ & $\begin{array}{l}0 \\
0 \\
0 \\
5\end{array}$ & $\begin{array}{c}A \& G \\
5 \\
12 \\
7 \\
4\end{array}$ & $\begin{array}{l}A \\
9 \\
2 \\
6 \\
4\end{array}$ & $\begin{array}{l}0 \\
0 \\
1 \\
6\end{array}$ & $\begin{array}{l}A \& G \\
2 \\
3 \\
0 \\
0\end{array}$ & $\begin{array}{l}2^{A} \\
1 \\
3 \\
0\end{array}$ & $\begin{array}{l}0 \\
0 \\
1 \\
4\end{array}$ & $\begin{array}{c}A \& G \\
7 \\
10 \\
0 \\
0\end{array}$ & $\begin{array}{l}A \\
3 \\
0 \\
8 \\
7\end{array}$ & $\begin{array}{l}0 \\
0 \\
2 \\
3\end{array}$ & $\begin{array}{c}A \& G \\
1 \\
0 \\
0 \\
0\end{array}$ & $\begin{array}{l}A \\
6 \\
7 \\
7 \\
6\end{array}$ & $\begin{array}{l}0 \\
0 \\
0 \\
1\end{array}$ \\
\hline
\end{tabular}

Table IV Biochemical reactions of $\mathrm{K}$. ozaenae strains isolated from patients with the organism persistently in the sputum

${ }^{1}$ Not all strains were tested

$\boldsymbol{A}=$ acid production

$\boldsymbol{G}=$ gas production 
from peptone water, ornithine decarboxylase, malonate utilization, and gluconate oxidation.)

The variabitity in results in the $\mathrm{KCN}$ and citrate tests may have been influenced by technique but those in sugar fermentation, especially with respect to gas production, could not have been influenced in this way. All of the strains submitted for capsular serotyping were examined using the extended series of biochemical tests noted previously. All strains produced acid from adonitol, salicin, xylose, and cellobiose. Two of 16 strains of $K$. ozaenae failed to produce acid from inositol.

The lysine-positive strains from patient $\mathrm{C}$ would be difficult to differentiate from $K$. edwardsii var atlantae using the criteria of Cowan et al (1960) and even those of Cowan and Steel (1961).

\section{SEROTYPES}

Twenty strains of Klebsiella were submitted to $\mathrm{Dr}$ I. Ørskov for serotyping. The 16 strains which were biochemically typed as $K$. ozaenae were all found to belong to capsular serotype 4 . The other four strains, three $K$. edwardsii and one $K$. edwardsii var atlantae, belonged to serotype 1 . These results agree with the observations of Cowan et al (1960).

RELATIONSHIP TO DISEASE

The relationship between the biochemical type of Klebsiella and the disease in the patient from whom they were isolated is shown in table $\mathrm{V}$.

The biotype most commonly isolated, $K$. aerogenes, was found in the sputum of 92 patients but in the majority of these was not of primary significance although it appeared to be significant in seven cases of pneumonia. $K$. ozaenae was the next commonest biotype and was found most frequently in patients with a history of chronic bronchitis. In about half of these cases it seemed to be related to the patient's disease. In most others its presence seemed to be of little significance except in five cases of primary pneumonia where, on the criteria shown in table I, it appeared to be of importance.

$K$. edwardsii var edwardsii was isolated from 19 patients and $K$. edwardsii var atlantae from seven. $K$. edwardsii strains were more often associated with disease than the other Klebsiella sp but even so in only seven of 11 cases of primary pneumonia did they seem to be of significance. Nevertheless all three cases of primary pneumonia due to $K$. edwardsii var atlantae were fatal as were two due to $K$. edwardsii var edwardsii. Three of the five patients who died were aged 60 or over and the other two aged 38 and 41 were moribund on admission to hospital.

One patient with $K$. ozaenae and four with $K$. aerogenes, where these were judged to be significant, died. The patient with $K$. ozaenae infection and two of those with $K$. aerogenes infection were aged over 70 but $K$. aerogenes was also isolated at necropsy from the lung of a man aged 57 and from a lung abscess in a child of $4 \frac{1}{2}$ years.

As in the other series quoted $K$. pneumoniae was rare but one female aged 69 who died of bronchopneumonia yielded the organism at necropsy.

\section{Discussion}

It is probable that the criteria as shown in table I tend to under- rather than overestimate an organism's significance. Even so the results with respect to $K$. edwardsii var edwardsii agree with the observations of Foster and Bragg (1962). In the present series $K$. edwardsii var atlantae was also associated with severe disease but more obviously than in Foster and Bragg's series. The discrepancy is doubtless due to the small numbers in each series. Hence $K$. edwardsii was associated more frequently with severe disease than other types whereas $K$. aerogenes was infrequently associated with severe disease.

\begin{tabular}{|c|c|c|c|c|c|c|c|}
\hline Organism & $\begin{array}{l}\text { Relationship } \\
\text { to Disease }\end{array}$ & $\begin{array}{l}\text { Acute } \\
\text { Exacerbation } \\
\text { of Chronic } \\
\text { Bronchitis }\end{array}$ & $\begin{array}{l}\text { Chronic } \\
\text { Bronchitis and } \\
\text { Pneumonia }\end{array}$ & $\begin{array}{l}\text { Primary } \\
\text { Pneumonia }\end{array}$ & $\begin{array}{l}\text { Acute } \\
\text { Bronchitis }\end{array}$ & $\begin{array}{l}\text { Other } \\
\text { (Secondary } \\
\text { Infection, eg, } \\
\text { in Tuberculosis } \\
\text { Lung Cancer, } \\
\text { Tracheostomy) }\end{array}$ & Total \\
\hline \multirow[t]{2}{*}{$K$. aerogenes } & . & 5 & 3 & $\begin{array}{r}7 \\
15\end{array}$ & 0 & 3 & 18 \\
\hline & - & 22 & 7 & 15 & 0 & 30 & 74 \\
\hline \multirow[t]{2}{*}{ K. ozaenae } & & 15 & 9 & 5 & 2 & 2 & 33 \\
\hline & - & 21 & 2 & 9 & 0 & 21 & 53 \\
\hline \multirow[t]{2}{*}{ K. edwardsii var edwardsii } & -. & 5 & 2 & 4 & 0 & 1 & 12 \\
\hline & - & 0 & 1 & 3 & 0 & 3 & 7 \\
\hline \multirow[t]{2}{*}{ K. edwardsii var atlantae } & $\ldots$ & 1 & 0 & 3 & 0 & 1 & 5 \\
\hline & - & 0 & 0 & 1 & 0 & 1 & 2 \\
\hline \multirow[t]{2}{*}{ K. pneumoniae } & & 1 & 1 & 1 & 0 & 0 & $\overline{3}$ \\
\hline & - & 0 & 0 & 0 & 0 & 2 & $209^{2}$ \\
\hline
\end{tabular}

Table V Relationship of Klebsiella to disease 
Darrell and Hurdle (1964) also were of the opinion that $K$. aerogenes was not a dangerous pathogen but had a significance in sputum similar to that of Escherichia coli. One interesting finding in the present survey is that from 1962 to 1964 only 19 strains of $K$. aerogenes were isolated from the 101 cases reviewed but in 1965-67 73 strains appeared in 108 cases reviewed. This would correlate well with the increasing use of ampicillin in the treatment of chest infections because $K$. aerogenes is frequently found in the sputum of patients who have been treated with this antibiotic. The prevalence of $K$. aerogenes in the sputum of patients previously treated with antibiotics was also noted by Darrell and Hurdle (1964).

Apart from the observations of Burns (1968) there have been no assessments made of the pathological significance of $K$. ozaenae since Cowan et al (1960) published their scheme of classification. Hence the present series is of interest in that full clinical data have been available on 86 patients from whose sputum $K$. ozaenae has been isolated. Perhaps the most fundamental observation has been that $K$. ozaenae has seldom (both during the period under review and subsequently) been isolated from patients who have not got chronic lung disease. Hence 47 of the 87 patients had chronic bronchitis and almost all of the 22 with 'other diseases' had either pulmonary tuberculosis or bronchial carcinoma. It would seem that a damaged respiratory tract provides a situation where $K$. ozaenae can colonize but, in over half these patients, not give rise to clinical disease. However, in 33 of the 86 cases, $K$. ozaenae was acting as a pathogen, including five cases of primary pneumonia where no other pathogen could be demonstrated. The proportion of patients in whom $K$. ozaenae was associated with disease $(38 \%)$ was higher than the proportion $(19.5 \%)$ of patients significantly infected with $K$. aerogenes but considerably less than the proportion of significant infections with $K$. edwardsii or K. pneumoniae.

Burns (1968) found Enterobacteria-specific precipitins in serum in relation to capsular type $4 K$. ozaenae in the sputum of patients with chronic destructive disorders and suggested a particular association of this species of Klebsiella with chronic secondary infection in these cases. It would seem that although $K$. ozaenae has not the pathological significance of $K$. edwardsii its presence requires careful clinico-bacteriological assessment in the individual patient and may point to the need for further investigation to define the nature and extent of the pulmonary lesion in a particular patient.

The classification of any group of organisms depends on the observation of reactions which are usually reproducible so that in diagnostic tables ' + ' usually indicates that $75 \%$ or more of strains perform that reaction and conversely ' - ' that $25 \%$ or less do not perform that reaction. For this reason it was thought to be of interest to see how reproducible the reactions characteristic of $K$. ozaenae were in strains repeatedly isolated from one patient. The results in table IV suggest that gas production from glucose is an unreliable characteristic as was recognized by Cowan and Steel (1961) who changed this characteristic from + (Cowan et al, 1960) to d. This variability of gas production (amongst other reactions studied) between different strains of $K$. ozaenae has been noted also by Ślopek and Durlakowa (1967) but such variation between isolates from the same patient has not been recorded.

The three negative MR results with the strains from patient A were possibly due to the fact that these strains grew poorly in the medium on these occasions. Growth in the presence of $\mathrm{KCN}$ was also an unreliable test in this laboratory as only $69 \%$ of strains were positive. However, with the exception of growth in the presence of $\mathrm{KCN}$ the strains, although showing considerable variations in some characteristics still fell clearly, on most occasions, within the biochemical classification of $K$. ozaenae. Biotype correlated well with capsular serotype in the strains examined by Dr Ørskov.

In the present series the biochemical classification of Klebsiella has been found helpful in the assessment of the significance of the presence of a Klebsiella in sputum. At a primary diagnostic level the presence of the three colonial forms associated with the different biotypes - the highly convex, large, sticky colonies of $K$. edwardsii, medium-sized, moist, creamy colonies of $K$. aerogenes (which may be difficult to differentiate from mucoid strains of $E$. coli), and the colourless, mucoid, and sometimes small colonies of $K$. ozaenae give the clinical bacteriologist early information which he can then correlate with the clinical state of the patient.

The presence of $K$. edwardsii (which should be differentiated from the occasional mucoid strain of Pseudomonas aeruginosa by the oxidase test) should always prompt urgent enquiry into the patient's condition, whereas with $K$. ozaenae the situation is less urgent and with $K$. aerogenes the colonial similarity to some strains of $E$. coli prompts the same sort of caution in correlating its presence with significant clinical disease as would be accorded to $E$. coli. This relationship between colonial form and pathogenicity may well assume greater importance if the classification scheme proposed by Bascomb, Lapage, Willcox, and Curtis (1971) gains acceptance in view of the fact that they grouped $K$. aerogenes, $K$. oxytoca, and $K$. edwardsii together in one taxon.

It has been suggested (Darrell and Hurdle, 1964) 
that $K$. edwardsii, $K$. pneumoniae, and possibly $K$. ozaenae should be reported as 'Friedländers' bacillus'. This would tend to overemphasize the importance of $K$. ozaenae but would err on the safe side in terms of arousing clinical suspicion as to the true nature of a patient's illness. It is, however, an unsatisfactory substitute for the direct consultation between bacteriologist and clinician which the isolation of such organisms should initiate.

The work was started as the result of discussions with the late Dr K. Patricia Carpenter who was to have written a section on the biotyping of Klebsiella sp. Her help and interest were greatly appreciated as was also the kindness of Dr I Ørskov in serotyping 20 strains of Klebsiella forwarded to her by $\mathrm{Dr}$ Carpenter. I am also grateful to $\mathrm{Mr} \mathrm{W}$. M. Brown, FIMLT, for careful technical assistance, to Mrs A. C. Ramage for secretarial assistance, and to my clinical colleagues for permission to review the records of cases admitted under their care.
References

Bascomb, S., Lapage, S. P., Willcox, W. R., and Curtis, M. A. 음 (1971). Numerical classification of the tribe Klebsiellae. J. gen. Microbiol., 66, 279-295.

Burns, M. W. (1968). 'Precipitins to Klebsiella and other enterobacteria in the serum of patients with chronic respiratory disorders. Lancet. 1, 383-385.

Cowan, S. T., and Steel, K. J. (1961). Diagnostic tables for the common medical bacteria. J. Hyg. (Lond.), 59, 357-372.

Cowan, S. T., and Steel, K. J. (1965). Manual for the Identification of $\stackrel{\mathbb{D}}{\varrho}$ Medical Bacteria. Cambridge University Press, Cambridge.

Cowan, S. T., Steel, K. J., Shaw, C., and Duguid, J. P. (1960). A classification of the Klebsiella group. J. gen. Microbiol., 23, 601- $\overrightarrow{0}$ 612.

Darrell, J. H., and Hurdle, A. D. F. (1964). Identification and clinical significance of Klebsiella species in chest infections. J. clin. Path., 17, 617-621.

Fallon, R. J. (1968). Klebsiellae in chronic respiratory disease (Letter). Lancet, 1, 641-642.

Foster, W. D., and Bragg, J. (1962). Biochemical classification of Klebsiella correlated with the severity of the associated disease. J. clin. Path., 15, 478-481.

Rawlins, G. A. (1953). Liquefaction of sputum for bacteriological examination. Lancet, 2, 538-539.

Slopek, S., and Durlakowa, I. (1967). Studies on the taxonomy of $\rightarrow$ Klebsiella bacilli. Arch. Immunol. Ther. exp., 15, 481-487. 